\title{
STUDY OF FUNCTIONAL OUTCOME OF DISCECTOMY FOR LUMBAR DISC PROLAPSE
}

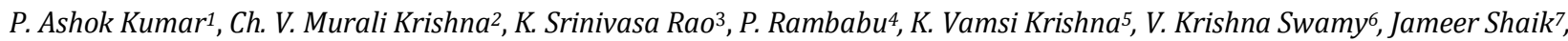 \\ K. Ramakrishna ${ }^{8}$
}

1Professor, Department of Orthopaedics, King George Hospital, Andhra Medical College, Visakhapatnam, Andhra Pradesh. ${ }^{2}$ Assistant Professor, Department of Orthopaedics, King George Hospital, Andhra Medical College, Visakhapatnam, Andhra Pradesh. ${ }^{3}$ Assistant Professor, Department of Orthopaedics, King George Hospital, Andhra Medical College, Visakhapatnam, Andhra Pradesh. ${ }_{4}^{4}$ Assistant Professor, Department of Orthopaedics, King George Hospital, Andhra Medical College, Visakhapatnam, Andhra Pradesh. ${ }_{5}^{5}$ Assistant Professor, Department of Orthopaedics, King George Hospital, Andhra Medical College, Visakhapatnam, Andhra Pradesh. 6 Junior Resident, Department of Orthopaedics, King George Hospital, Andhra Medical College, Visakhapatnam, Andhra Pradesh. $7 J u n i o r$ Resident, Department of Orthopaedics, King George Hospital, Andhra Medical College, Visakhapatnam, Andhra Pradesh. 8Junior Resident, Department of Orthopaedics, King George Hospital, Andhra Medical College, Visakhapatnam, Andhra Pradesh.

\section{ABSTRACT}

\section{BACKGROUND AND OBJECTIVES}

Numerous retrospective and some prospective review of open disc Surgeries are available. The results of these series vary greatly with good results ranging from $46-97 \%$ and re-operation rate of $9 \%$. The need for this study is to evaluate the results of discectomy for Lumbar disc prolapse. With regard to patient's post-operative subjective evaluation of low back pain and radicular symptoms, the objective physical findings and the complications are evaluated

\section{METHODS}

30 cases of lumbar disc prolapse treated with fenestration and discectomy treated in Andhra Medical College and King George Hospital, Visakhapatnam were studied. Japanese Orthopaedic Association Low Backache score was used to assess the outcome. Preoperative and Post-operative scores were taken and the rate of improvement in terms of percentage was calculated.

\section{RESULTS}

In our study we achieved $86 \%$ excellent-to-good results, $10 \%$ of fair results with a complication rate of $3.3 \%$ only. The results were comparable to other studies.

\section{INTERPRETATION AND CONCLUSION}

There are many new techniques for treatment of lumbar disc prolapse, but conventional standard discectomy through a fenestration is still the most acceptable method even today. Various studies have shown $91 \%$ of patients had excellent, good and satisfactory outcome; $9 \%$ of patients had moderate and poor outcomes.

\section{KEYWORDS}

Fenestration, Discectomy, Lumbar Disc prolapse.

HOW TO CITE THIS ARTICLE: Kumar PA, Krishna CVM, Rao KS, et al. "Study of functional outcome of discectomy for lumbar disc prolapse”. J. Evolution Med. Dent. Sci. 2016;5(42):2697-2702, DOI: 10.14260/jemds/2016/607

\section{INTRODUCTION}

Humans have been plagued by back and leg pain since the beginning of recorded history. Back pain is now appearing as a modern pandemic. Upto $80 \%$ of people are affected by this symptom at some time in their lives. Impairments of the back and spine are ranked as the most frequent cause of limitation of activity in people younger than 55 years by the national centre for health statistics. Intervertebral disc disease and disc herniation are most prominent in otherwise healthy people in the $3^{\text {rd }}$ and $4^{\text {th }}$ decades of life. It accounts for a majority of cases of low backache seen by an orthopaedician in clinical practice and is a major contributor of functional disability.

This study is a thorough clinico-radiological and surgical study of thirty patients with severe long-standing low back pain secondary to prolapse of the lumbar intervertebral disc, treated by fenestration and discectomy.

Financial or Other, Competing Interest: None.

Submission 18-11-2015, Peer Review 24-11-2015,

Acceptance 26-11-2015, Published 25-05-2016.

Corresponding Author:

Dr. P. Ashok Kumar,

\# B-98, Dayal Nagar,

Visakhapatnam-530043,

E-mail: ashok_ortho59@rediffmail.com

DOI: $10.14260 /$ jemds/2016/607
This study is a thorough clinico-radiological and surgical study of thirty patients with severe long-standing low back pain secondary to prolapse of the lumbar intervertebral disc, treated by fenestration and discectomy.

\section{OBJECTIVES}

1. To study the outcome of the surgical management of lumbar intervertebral disc prolapse in adults by fenestration and discectomy.

2. To know the complications following fenestration and discectomy for lumbar intervertebral disc prolapse and compare them with available literature.

\section{MATERIALS AND METHODS}

Cases satisfying the following inclusion and exclusion criteria were studied.
Inclusion Criteria
a. Age 18-55 years.
b. Males and females.
c. Failure to respond to non-operative treatment.
d. Presence of positive root tension signs with or without neurological deficits.
e. MRI scan showing disc prolapse. 


\section{Exclusion Criteria}

a. Prior lumbar spine surgery.

b. Vertebral fractures.

c. Radiological evidence of facet joint arthritis.

All the patients were assessed clinically. A detailed history was obtained and they were subjected to a thorough clinical examination. Radiological investigations (Plain X-ray and MRI) were carried out to confirm the diagnosis and know the level of the lesion. The patients were also assessed preoperatively and postoperatively with the Japanese Orthopaedic Association low backache score.

All patients underwent conventional open fenestration and discectomy surgery in the prone position. The level and type of disc protrusion was observed intra-operatively. Postoperatively, the patients were followed up in the immediate post-operative period, 1 month and 6 months after the surgery.

The Japanese Orthopaedic Association low backache score (Appendix-II) was used pre- and post-operatively to assess the outcome analysis of functional status.

The outcome designation of;

Good. 75 to $100 \%$ improvement.

Fair. 50 to $74 \%$ improvement.

Poor. Below 49\%.

The improvement in pain and neurological deficit were recorded. Peri- and post-operative complications if any were noted. Significance of postoperative changes were assessed by the Chi-square test.

\section{OPERATIVE PROCEDURE}

Standard Open Fenestration and Discectomy:

Anaesthesia

Spinal anaesthesia was used.

\section{Position of the Patient}

The patient was placed prone in the knee-chest position.

\section{Approach}

A midline vertical incision over the interspace of $8-10 \mathrm{cms}$ is made the paraspinal muscles retracted.

The supraspinous ligament is incised over the affected disc space. The laminae are partially nibbled and the Ligamentum Flavum is removed using a Kerrison Rongeur.

After the cord has been exposed adequately, the Dura is retracted medially and nerve root is inspected. The nerve root is retracted medially using a blunt dissector in order to visualize the underlying disc. It may be seen as an extruded fragment or a bulging posterior longitudinal ligament and disc is removed with disc removal forceps.

\section{After Care}

Patient was allowed to turn in bed. Pain was controlled with injectable and oral NSAIDS. Postoperative antibiotics were administered for two days. Patient was allowed out of bed next day within the limits of the pain. Sutures were removed after 10 days. Patient was advised isometric abdominal and lower extremity exercises. At discharge patient was advised not to strain the back. Patients were instructed to minimize sitting and riding in a vehicle. Lifting weight, bending and stooping were prohibited and gentle isotonic leg exercises were started.

Patients with jobs requiring prolonged sitting and minimal lifting were allowed to return to work after 6 to 8 weeks and those with jobs requiring heavy labour were asked to modify their occupation. They were also advised not to do stretching exercises.

\section{RESULTS AND ANALYSIS}

This study consists of 30 cases of lumbar disc prolapse treated by fenestration and discectomy in 2012-2014. The mean followup was 7.5 months ranging from 6 to 14 months

The age of these patients ranged from 28 to 60 years. Female patients were aged between 28 and 60 years. Males were aged between 30 years and 50 years.

\begin{tabular}{|c|c|c|}
\hline Age & No. of Cases & \% \\
\hline $20-40$ & 15 & $50 \%$ \\
\hline $41-60$ & 15 & $50 \%$ \\
\hline$>60$ & 0 & $0 \%$ \\
\hline Total & $\mathbf{3 0}$ & $\mathbf{1 0 0} \%$ \\
\hline \multicolumn{3}{|c|}{ Table 1: Age Distribution } \\
\hline
\end{tabular}

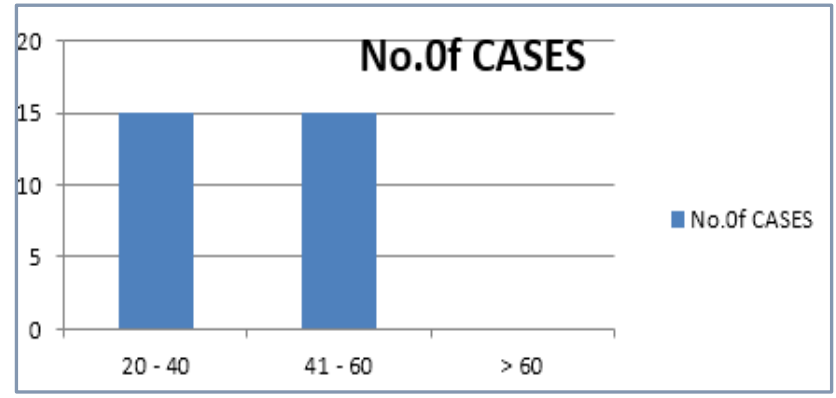

\begin{tabular}{|c|c|c|}
\hline Sex & No. of Cases & \% \\
\hline Male & 13 & $43.33 \%$ \\
\hline Female & 17 & $56.66 \%$ \\
\hline Total & $\mathbf{3 0}$ & $\mathbf{1 0 0} \%$ \\
\hline \multicolumn{2}{|c|}{ Table 2: Sex Distribution } \\
\hline
\end{tabular}

\begin{tabular}{|c|c|c|}
\hline Symptoms & No. of Cases & \% \\
\hline Low backache & 26 & $86.66 \%$ \\
\hline Radicular pain & 30 & $100 \%$ \\
\hline Paraesthesias & 20 & $66.66 \%$ \\
\hline C/O weakness & 4 & $13.33 \%$ \\
\hline Bladder/Bowel & 0 & 0 \\
\hline \multicolumn{2}{|c|}{ Table 3: Distribution of Symptoms } \\
\hline
\end{tabular}

On examination, a positive SLRT was the most common finding followed by restricted spinal movements and neurological deficits.

\begin{tabular}{|c|c|c|}
\hline Signs & No. of Cases & \% \\
\hline Positive SLRT & 30 & $100 \%$ \\
\hline Para spinal muscle spasm & 25 & $83.33 \%$ \\
\hline Restricted movements & 26 & $86.6 \%$ \\
\hline Motor deficits & 7 & $23.33 \%$ \\
\hline Sensory deficits & 13 & $43.33 \%$ \\
\hline Absent knee jerk & 10 & $33.33 \%$ \\
\hline Absent ankle jerk & 2 & $6.66 \%$ \\
\hline Bladder/Bowel involvement & 0 & 0 \\
\hline \multicolumn{2}{|c|}{ Table 4: Distribution of Signs } \\
\hline
\end{tabular}




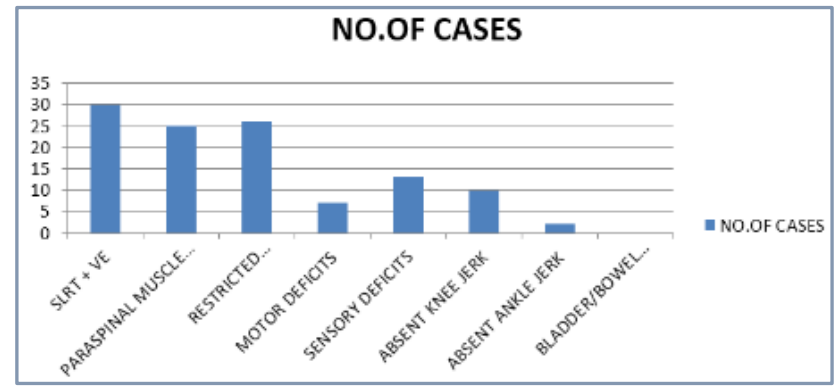

\begin{tabular}{|c|c|c|}
\hline $\begin{array}{c}\text { Pre-op JOA } \\
\text { Score }\end{array}$ & No. of Cases & \% \\
\hline $0-5$ & 3 & $10 \%$ \\
\hline $6-10$ & 27 & $90 \%$ \\
\hline $11-15$ & 0 & 0 \\
\hline \multicolumn{2}{|c|}{ Table 5: Distribution of JOA Score Pre-op } \\
\hline
\end{tabular}

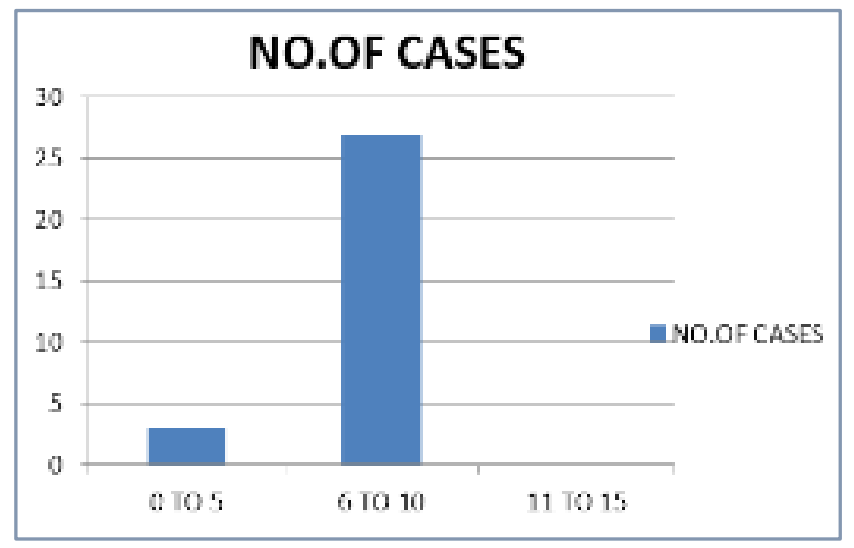

\begin{tabular}{|c|c|c|}
\hline Level of Disc Prolapse & No. of Cases & $\mathbf{\%}$ \\
\hline L3 - L4 & 1 & $3.33 \%$ \\
\hline L4 - L5 & 20 & $66.66 \%$ \\
\hline L5 - S1 & 9 & $30 \%$ \\
\hline Total & $\mathbf{3 0}$ & \\
\hline Table 6: Distribution of Level of Disc Prolapse \\
\hline
\end{tabular}

L4-5 disc prolapse was the commonest level of involvement in our study followed by L5-S1.

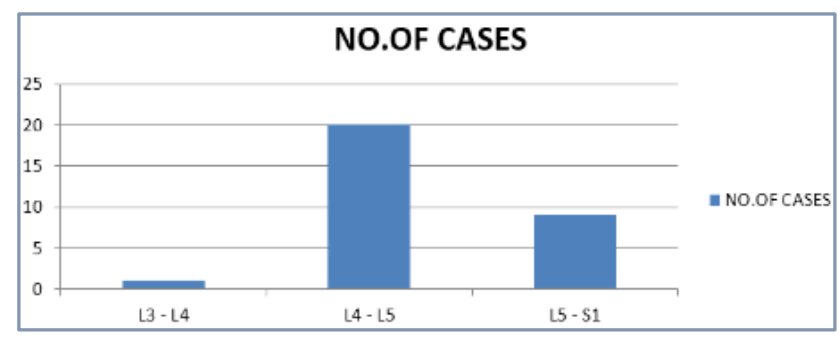

\begin{tabular}{|c|c|c|}
\hline Complications & No. of Cases & \% \\
\hline Superficial wound infection & 2 & $6.6 \%$ \\
\hline Dural rupture & 1 & $3.3 \%$ \\
\hline Discitis & 1 & $3.3 \%$ \\
\hline Table 7: Distribution of Complications \\
\hline
\end{tabular}

The post-operative JOA score after a mean follow-up of 8.2 months is given below:

\begin{tabular}{|c|c|c|}
\hline Post-op JOA Score & No. of Cases & $\%$ \\
\hline $0-5$ & 0 & 0 \\
\hline $6-10$ & 4 & $13.33 \%$ \\
\hline $11-15$ & 26 & $86.66 \%$ \\
\hline \multicolumn{2}{|c|}{ Table 8: Distribution of Post-Op JOA Score } \\
\hline
\end{tabular}

\begin{tabular}{|c|c|c|}
\hline Outcome & No. of Cases & \% \\
\hline Good $(>75 \%)$ & 26 & $86.6 \%$ \\
\hline Fair $(50-75 \%)$ & 3 & $10 \%$ \\
\hline Poor $(<50 \%)$ & 1 & $3.4 \%$ \\
\hline \multicolumn{2}{|c|}{ Table 9: Distribution of Outcome } \\
\hline
\end{tabular}

5 out of 7 patients with motor deficits before surgery had improved power post-operatively.

Out of 13 patients who had sensory deficit, 10 improved; 3 patients had persistent sensory deficit post-operatively.

\begin{tabular}{|c|c|c|c|}
\hline $\begin{array}{c}\text { Neurological } \\
\text { Deficit }\end{array}$ & $\begin{array}{c}\text { Total no. of } \\
\text { Cases }\end{array}$ & Improved & $\begin{array}{c}\text { Not } \\
\text { Improved }\end{array}$ \\
\hline Sensory & 13 & 10 & 3 \\
\hline Motor & 7 & 5 & 2 \\
\hline \multicolumn{4}{|c|}{ Table 10 } \\
\hline
\end{tabular}

Improvement in neurological status was correlated with the duration of symptoms.

The outcome according to the JOA score was correlated and analysed for the following variables.

Sex.

Age.

Duration of symptoms.

Neurological deficit.

\section{Correlation with Sex}

15 out of 17 females had good outcomes, 11 out of the 13 males had good outcome and 1 male patient had a poor outcome. This difference in outcome between male and female patients was not statistically significant.

\section{Correlation with Age}

One patient of less than 40 years had a poor outcome; 15 patients of more than 40 years had good outcome. The difference between the two groups was not statistically significant.

\section{Correlation with Duration of Symptoms}

Five cases of less than 6 months' duration had good outcome, 21 cases with more than 6 months' duration of symptoms had good outcome. There was no statistically significant difference between the two groups.

\section{Correlation with Neurological Deficit}

\begin{tabular}{|c|c|c|c|}
\hline Outcome & Neurological Deficit & \multicolumn{2}{|c|}{$\begin{array}{c}\text { No Neurological } \\
\text { Total Cases Deficit }\end{array}$} \\
\hline Poor & 1 & 0 & 1 \\
\hline Fair & 2 & 1 & 3 \\
\hline Good & 17 & 9 & 26 \\
\hline Total & $\mathbf{2 0}$ & $\mathbf{1 0}$ & $\mathbf{3 0}$ \\
\hline
\end{tabular}

One patient with poor outcome had neurological deficit; there were no poor outcomes among those who had no 
neurological deficits. The difference between the two groups was however not statistically significant.
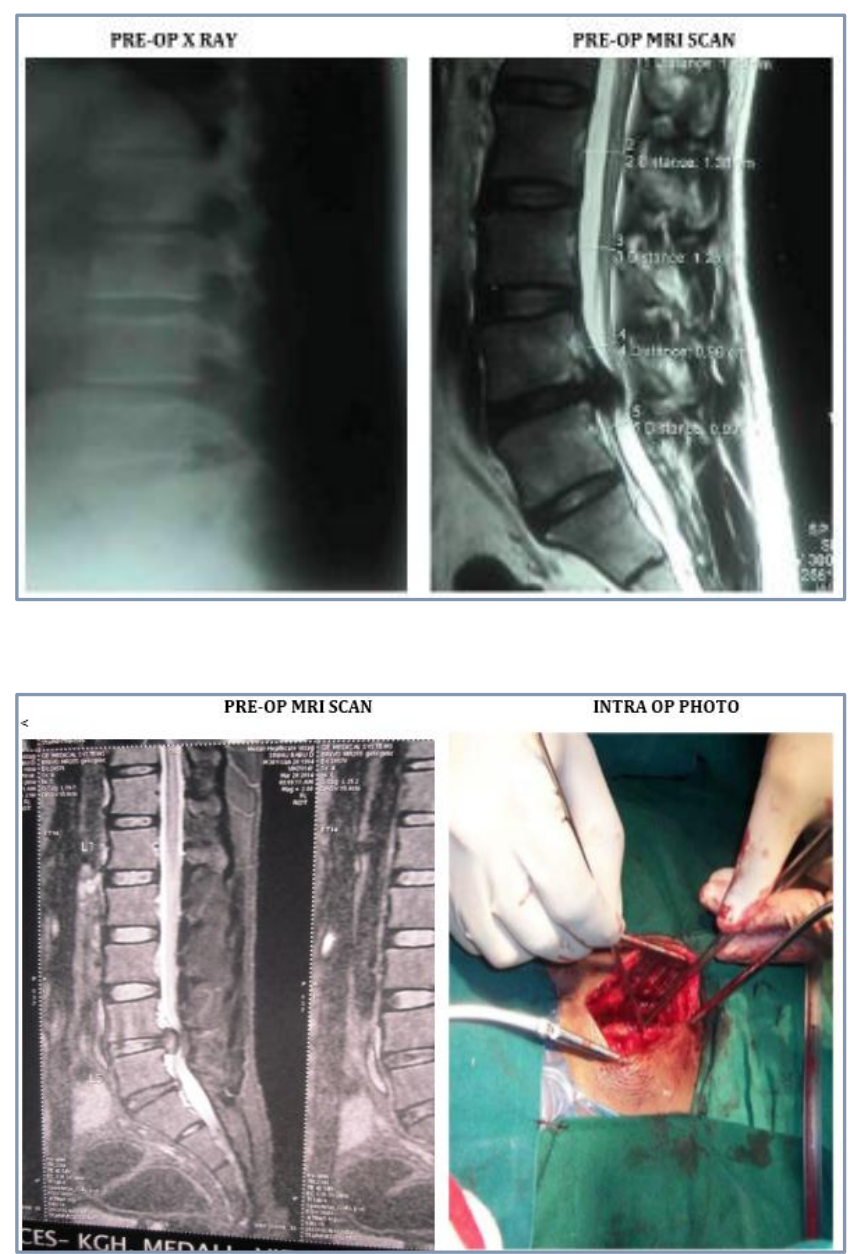

\section{DISCUSSION}

Low back disorders have become the most common musculoskeletal disorder with a major impact on the costs of health care and are a major source of disability.

One must recognize that low back pain is a symptom that has many causes, the commonest being a protruded disc. The origins of disc related sciatica with its clear morphologic and clinical neurologic findings were not recognized until the $20^{\text {th }}$ century. After Mixter and Barr. ${ }^{1}$ in 1934 described disc protrusions and showed the effectiveness of surgery in its management, there has been an increasing enthusiasm to solve sciatica problems surgically by disc excision.

In 2012, Shi J et al evaluated the long term outcome of sixty patients (Mean follow-up, 214 months) who underwent fenestration and discectomy for lumbar disc prolapse. At final followup, patients were rated as 'excellent' $(n=31)$, 'good' $(n=13)$, 'fair' $(n=5)$ and 'poor' $(n=11)$ using the StaufferCoventry criteria (60).

However, the results of good outcome after lumbar disc excision varies in literature from 51 to $89 \% .2,3,4$ There are a considerable number of failed back surgeries too, which may require revision surgery. The recurrence rate for lumbar disc excision varies from $6 \%$ to $11 \%$ in various studies. ${ }^{3}$

There was no significant difference in the operation time and blood loss between fenestration and laminotomy discectomy groups. ${ }^{5}$

This implies that there are many factors which influence the outcome of lumbar disc surgery. Therefore, emphasis should be laid on proper patient selection. For a great majority of patients with sciatica due to disc prolapse conservative treatment provides satisfactory relief from symptoms. In evaluating disc disease, the natural history should be taken into account which reveals that surgery plays only a palliative role in its management.

Lumbar disc herniation shows a favourable response to conservative treatment even in the presence of some neurological deficit. 6

Hence, any surgical intervention without appropriate conservative therapy leads to unnecessary surgery and also to poor outcome. However, a protracted conservative regimen in the presence of severe radicular symptoms should be avoided since these increases morbidity and reduces the chances of a successful outcome. A longer preoperative interval in patients with chronic sciatica was associated with a less predictable outcome. 4

In the peripheral institutions, fenestration with disc excision is quite reasonable method to surgically treat the indicated cases of prolapsed disc and this procedure can be well performed even by an average spinal surgeon with adequate experience in the field of disc surgery. ${ }^{7}$

The advantages offered by the fenestration technique are the maintenance of spinal stability, early mobility and thus early return to work. ${ }^{8}$

It is therefore the clinician's task to properly select for surgery, the patients with appropriate indications who are expected to have symptomatic relief from the surgery with limited risk and least possible expense.

Better investigative modalities (Myelography/CT/MRI) have led to more accurate diagnosis of disc lesions. They have revolutionized the diagnosis of spinal disease by the accurate visualization of all structures within the neural canal. In addition, it offers the opportunity to outline the neural foramen and extra foraminal areas and thus guides the surgeon in planning a precise surgical correction, preventing unnecessary exploration of uninvolved levels. Results of lumbar disc surgery are excellent when there is agreement between clinical presentation and imaging studies.

In our study, we used the Japanese Orthopaedic Association low backache score (Appendix II) to evaluate our results. This score was used as it is simple, which assess the patient's outcome both subjectively and objectively. It also helps in correlating the results to various factors that may influence the outcome such as age, sex, duration of symptoms, etc.

\section{Patient Population}

In our study $43.33 \%$ of the cases were males and $56.66 \%$ females.

\begin{tabular}{|c|c|c|c|}
\hline Sex & Pappas et al & R. Davis & Present Study \\
\hline Male & $61 \%$ & $64 \%$ & $43.33 \%$ \\
\hline Female & $39 \%$ & $36 \%$ & $56.66 \%$ \\
\hline
\end{tabular}

Females were affected more commonly than males in our study, which is not in accordance with studies by Pappas and Richard Davis who had a male preponderance. Richard Davis had a mean age of 42 years range from 16 to 77 years. Pappas et al had a mean age of 42 years range of 15 to 83 years.

The event or precipitating factor that accounted for most of the cases was inappropriate lifting of weight (30\%); 5\% had 
a history of fall. In Pappas et al study, lifting weight was the event in $31.4 \%$ of cases followed by falls (10\%), sports injuries (10\%) and automobile accidents (6.1\%).

The L4-5 was the most commonly involved in our study.

\begin{tabular}{|c|c|c|c|c|}
\hline \multicolumn{2}{|c|}{$\begin{array}{c}\text { Level of Prolapse } \\
\text { Richard Davis }\end{array}$} & $\begin{array}{c}\text { Pappas et } \\
\text { al }\end{array}$ & $\begin{array}{c}\text { Guptha et } \\
\text { al }\end{array}$ & $\begin{array}{c}\text { Present } \\
\text { Study }\end{array}$ \\
\hline L1-2 & $0.2 \%$ & - & - & - \\
\hline L2-3 & $0.9 \%$ & $2 \%$ & - & - \\
\hline L3-4 & $4.4 \%$ & $9 \%$ & - & 3.33 \\
\hline L4-5 & $46.7 \%$ & $49 \%$ & $35.2 \%$ & $66.66 \%$ \\
\hline L5-S1 & $47 \%$ & $40 \%$ & $22.3 \%$ & $30 \%$ \\
\hline Multiple Level & $0.8 \%$ & - & $44.5 \%$ & - \\
\hline
\end{tabular}

In our study, we achieved $86.6 \%$ good outcomes and $10 \%$ fair outcomes. We had $3.4 \%$ of poor outcome as compared to Pappas et al and R. Davis who had $6.4 \%$ and $3.3 \%$ poor results respective.

\begin{tabular}{|c|c|c|c|}
\hline Outcome & Richard Davis & Pappas et al & Present Study \\
\hline Good & $89 \%$ & $77.3 \%$ & $86.6 \%$ \\
\hline Fair & $7.7 \%$ & $15.5 \%$ & $10 \%$ \\
\hline Poor & $3.3 \%$ & $6.4 \%$ & $3.4 \%$ \\
\hline
\end{tabular}

In our study, there was about $13 \%$ incidence of complications with two cases of superficial wound infection, one case of dural rupture and one case of discitis.

\begin{tabular}{|c|c|c|c|}
\hline Complications & Richard & Pappas et & Present \\
\hline Wound infection & $25(2.1 \%) 45(1.8 \%)$ & $2(6.6 \%)$ \\
\hline Dural tear & 6 & 6 & $1(3.3 \%)$ \\
\hline Discitis & - & 3 & $1(3.3 \%)$ \\
\hline Paraplegia & 4 & - & - \\
\hline Pseudomeningocele & - & 3 & - \\
\hline Arterial injuries & - & 2 & - \\
\hline Small intestine & - & 1 & - \\
\hline Pulmonary & - & 6 & - \\
\hline Paralytic ileus & 5 & - & - \\
\hline
\end{tabular}

Various factors were correlated with outcome.

\section{Sex}

In our study, we found that there was no significant correlation between outcome and the sex. Weber in his study found that the female sex was associated with poor outcomes. ${ }^{6}$

\section{Age}

One case with poor outcome was seen in patient $<40$ years of age in our study. However, the outcome of patients $>40$ years of age was statistically not significantly different from the other group. Matti Hurme et al found that age older than 40 years was associated with poor outcome. Weber found that age was not predictive of outcome. ${ }^{6}$

\section{Duration of Symptoms}

In our series, one case which had a poor outcome had a preoperative duration of symptoms of $<6$ months. The statistical difference was however not significant between those with less than 6 months and more than 6 months duration of symptoms. A Naylor in his study found that a longer preoperative duration of symptoms was associated with less favourable outcome following surgery. ${ }^{4}$ a contained disc protrusion was almost three times more likely to need revision surgery compared with extruded or sequestrated discs. ${ }^{9}$

\section{Neurological Deficit}

Surgical outcome was not significantly affected with absence or presence of neurological deficit in our study.

Overall, in our study we had a favourable outcome following fenestration and discectomy for lumbar disc prolapse. A comparison of our results to those of microdiscectomy is given below.

\begin{tabular}{|c|c|c|c|}
\hline Authors & Good & Fair & Poor \\
\hline Ebeling et al (Microdiscectomy) & $73 \%$ & $19 \%$ & $9 \%$ \\
\hline R. Silvers (Microdiscectomy) & $95.5 \%$ & $3 \%$ & $1.5 \%$ \\
\hline Caspar et al (Microdiscectomy) & $74 \%$ & $18.1 \%$ & $7.9 \%$ \\
\hline Nagi et al (Fenestration) & $93.3 \%$ & $5 \%$ & $1.7 \%$ \\
\hline Present study (Fenestration) & $86.6 \%$ & $10 \%$ & $3.4 \%$ \\
\hline
\end{tabular}

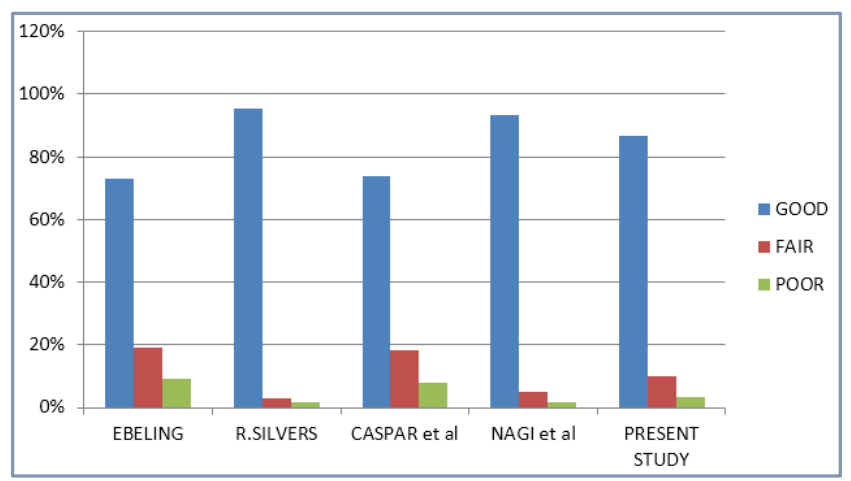

\section{CONCLUSION}

Several conclusions can be drawn from our study. The fenestration and discectomy is an extremely useful and effective surgery for treatment of lumbar disc prolapse. Consistently good results (86.6\%) in our study could be attributed to proper selection of cases and a meticulous surgical protocol. The results of lumbar discectomy are good when there is agreement between clinical presentation and imaging studies as was seen in our study. All our patients had radicular pain at presentation

The variables which were found to have no correlation with outcome were age, sex, duration of symptoms and neurological deficits.

The Japanese Orthopaedic Association low backache score appears to be a useful tool for evaluation of disc surgery. Widespread use of this score will allow different studies and procedures to be compared more objectively to improve the outcome of disc surgery. In addition to the postoperative score, change of the postoperative score as compared to the preoperative score is also a useful indicator of outcome. The only limitation of this study was a small sample size.

In our study, we achieved results comparable to that achieved with microdiscectomy. Microsurgical techniques may have some advantages in terms of a less invasive approach, shorter hospital stay, etc., but one must understand the demands, requirements and limitations of this technique. It also has a long learning curve and is technically a more demanding procedure in terms of surgical skills of the surgeon and equipment required and thus is available only in 
multispecialty hospitals. Also fenestration and discectomy is more cost effective than microdiscectomy.

Therefore, for the Indian scenario fenestration and discectomy is still the "Gold Standard" in operative treatment of lumbar disc prolapse.

\section{REFERENCES}

1. Mixter WJ, Barr JS. Rupture of the intervertebral disc with involvement of the spinal canal. N Engl J Med 1934;211:210-5.

2. Junge A, Dvorak J, Ahrens S. Predictors of bad and good outcomes of lumbar disc surgery: a prospective clinical study with recommendations for screening to avoid bad outcomes. Spine 1995;20(4):460-8.

3. Davis RA. A long-term outcome analysis of 984 surgically treated herniated lumbar discs. J Neurosurg 1994;80(3):415-21.
4. Naylor A. The late results of laminectomy for lumar disc proplapse: a review after ten to twenty-five years. J Bone Joint Surg Br 1974;56(1):17-29.

5. Parisa Azimi, Hassn-Reza Mohammadi, Soharab Sadeghi. Functionality status and surgical outcome of fenestration versus laminotomy discectomy in patients with lumbar disc herniation. Ir JNS 2015;1(1):23-7.

6. Weber H. Lumbar disc herniation-a controlled prospective study with ten years of observation. Spine 1983;8(2):131-40.

7. Sangwan SS, Kundu ZS, Raj Singh, et al. Lumbar disc excision through fenestration. IJO 2006;40(2):86-9.

8. Nagi ON, Anil Sethi, Gill SS. Early results of discectomy by fenestration technique in lumbar disc prolapsed. IJO 1985;19(1):15-9.

9. Morgan-Hough CVJ, Jones PW, Eisenstein SM. Primary and revision lumbar discectomy: a 16-year review from one centre. J Bone Joint Surg Br 2003;85(6):871-4. 